\title{
Por una historia transnacional del tiempo presente: Hacer la revolución. Guerrillas latinoamericanas, de los años sesenta a la caída del Muro
} ₹

For a transnational history of the present time:

Make the Revolution. Latin American

Guerrillas, from the Sixties to the Fall of the Wall

\author{
Grethel DomeneCh \\ Universidad lberoamericana \\ México \\ Correo: domenech22Ib@gmail.com \\ DOI: 10.48 I02/hyg.vi57.373
}

Reseńa recibida: $18 / 08 / 2020$

Reseńa aceptada: I 5/02/202 I

Marchesi, Aldo. Hacer la revolución. Guerrillas latinoamericanas, de los años sesenta a la caída del Muro, Buenos Aires, Siglo XXI Editores Argentina, 2019, 267 Pp.

G $\mathrm{n}$ los estudios sobre América Latina a partir de los años semirada transnacional que reconstruya los procesos políticos, ideológicos, intelectuales y culturales que vivió la región, teniendo en cuenta las complejidades de un contexto de Guerra Fría marcado por el ascenso de diversas agendas políticas. Una de las temáticas que más ha cobrado relevancia en ese sentido es el análisis de los movimientos guerrilleros o revolucionarios que comenzaron a desplegarse tras 1959 en el continente. No obstante, la fuerte carga de afectos a su alrededor, la cercanía temporal, el llamado 
fracaso de muchos de estos movimientos y la falta de fuentes para historizarlos, son algunas de las escabrosas cuestiones que dificultan el trabajo del historiador del tiempo presente.

Hacer la revolución. Guerrillas latinoamericanas, de los años sesenta a la caída del Muro, último libro del historiador uruguayo Aldo Marchesi, logra sortear muchas de estas dificultades y viene a ubicarse como un referente imprescindible de esta mirada transnacional. Sus libros anteriores: El presente de la dictadura: estudios y reflexiones a 30 años del golpe de estado en Uruguay, compilado con Vania Markarian, Álvaro Rico y Jaime Yaffé (2004) y El Uruguay inventado: la política audiovisual de la dictadura, reflexiones sobre su imaginario (2001), ya mostraban importantes inquietudes en torno a la política latinoamericana de la segunda mitad del siglo xx, específicamente la implementación de agendas autoritarias y militares en Uruguay.

La propuesta de Marchesi articula de forma precisa y atrayente una historia transnacional de los movimientos guerrilleros y de la izquierda en el Cono Sur desde 1959 hasta 1989. En sus propias palabras, la intención es examinar "el surgimiento, desarrollo y fracaso de una red de organizaciones de jóvenes militantes de izquierda que, a fines de los sesenta y comienzos de los setenta, promovieron la violencia política organizada y las estrategias transnacionales como único camino para alcanzar el cambio social. La investigación sigue la trayectoria de militantes argentinos, chilenos, uruguayos y, en menor medida, brasileńos y bolivianos en la construcción de una red regional de organizaciones armadas que actuó durante más de una década" (p. 6). La edición original del libro es de 2017, con el título de Latin America's Radical Left. Rebelion and Cold War in the Global 1960s por Cambridge University Press, lo cual nos da una idea más precisa del acercamiento de Marchesi, quien tiene en cuenta categorías esenciales para pensar su campo de estudio: guerra fría, rebelión, izquierda y guerrillas. Sin duda alguna, la principal contribución del texto la encontramos en su mirada transnacional que permite analizar las 
confluencias de estos movimientos y las nuevas formas de hacer política que se expandieron por América Latina en aquel entonces. Al ser un proceso que tiene intrínseca una identidad regional se hace imprescindible este tipo de aproximaciones. Tal como deja expresado el autor, su fin es "contribuir a tres campos políticos vinculados a la historia latinoamericana reciente: la revuelta global de los sesenta, la historia de la izquierda latinoamericana y el surgimiento del autoritarismo en el Cono Sur” (p. 8).

Una de las cuestiones que desde los primeros capítulos se entreteje es la impronta de la Revolución cubana en estos movimientos. El autor no cae en la trampa de pensar al proceso cubano como un referente monolítico; al contrario, nos ayuda a desmontar muchos de los lugares comunes al respecto. La idea de "hacer la revolución" en América Latina se fue catalizando cada vez más tras el triunfo de los barbudos cubanos en 1959. Las expectativas y posibilidades que creó la Revolución cubana han sido estudiadas, la mayoría de las veces, desde una mirada romántica y nostálgica. Marchesi, en cambio, contribuye a romper con esto y entender de forma más compleja el tema. Como bien expresa: "Cuba también se leyó con distancia crítica" (p. 13). Para ello, el primer capítulo, “Cómo es la revolución sin la Sierra Maestra?”, ahonda en las posturas y disensos de militantes chilenos, argentinos y uruguayos que comienzan a percibir que la geografía, la demografía y las estructuras socioeconómicas de sus países eran diferentes al caso cubano y que por lo tanto su modelo no podía calcarse de manera exacta.

Las organizaciones o focos guerrilleros que comenzaron a conformarse a partir de los sesenta se identificaron como una "Nueva Izquierda" que se apartó de las visiones más ortodoxas de la izquierda tradicional que sólo reconocía la lucha de clases o la llegada al poder mediante partidos políticos. El fracaso de la izquierda clásica hizo que los nuevos movimientos comenzaran a tener una identidad propia que recurrió a la lucha armada, a la creación de focos rurales, a establecer redes intelectuales mediante 
revistas y encuentros y a nuevas lecturas teóricas como las de Ernesto Guevara o Régis Debray. Esta nueva identidad contó con una cultura política que Aldo Marchesi se propone indagar:

Para desarrollar esas contribuciones me propongo rastrear el origen y la conformación de una cultura política transnacional al calor de los diálogos y encuentros de militantes de la nueva izquierda en la región desde mediados de los sesenta hasta el golpe de estado de 1976 en la Argentina. Esa cultura política estuvo vinculada al resultado de los ensayos de experiencias políticas locales, los movimientos de exilio en la región y la creciente regionalización del autoritarismo (pp. 21-22).

Como bien señala Marchesi, esa cultura política estuvo permeada no sólo por las lecturas de peregrinos intelectuales a Cuba, dígase Carlos María Gutiérrez o Jorge Ricardo Masetti, sino también por la presencia de ideologías troskistas o la influencia del pensamiento de Haya de la Torre, lo cual nos da la idea de un universo ideológico mucho más variado y rico de lo que solemos pensar: "[U]na cultura política transnacional entre los militantes de la región, que fue resultado del encuentro entre las distintas maneras en que experimentaron los procesos políticos y locales y sus interpretaciones de los procesos globales" (p. 227).

En la cartografía política e ideológica que realiza Aldo Marchesi en Hacer la revolución... destacan por igual lugares como La Habana, Montevideo o Bolivia y momentos como la Conferencia de la Organización de Solidaridad de los pueblos de África, Asia y América Latina en 1966 y la Conferencia de la Olas (Organización Latinoamericana de Solidaridad) en julio de 1967. Esos encuentros de solidaridad contribuyen a entender las zonas de conflictos de las distintas posturas en cuanto a la recepción de lo revolucionario, cómo se propagó la idea de una revolución continental y armada en América Latina, especialmente tras 1966, y cómo se asumió esa inmediatez necesaria de movimientos y pro- 
cesos revolucionarios por todo el sur también tras el impacto de la guerrilla boliviana del Che.

El foco de Marchesi se ubica en el Cono Sur; por ello propone "reconstruir el lugar que ocupó en los sesenta globales, ya que la emergencia de estos actores no puede explicarse a partir de la centralidad de lo ocurrido en Europa y los Estados Unidos" (p. 11). Las organizaciones de esa área que cobran especial importancia en las páginas del libro son el Movimientos de Liberación Nacional Tupamaros (MLN-T), el Movimiento de Izquierda Revolucionario chileno (MIR), el Partido Revolucionario de los Trabajadores-Ejército Revolucionario del Pueblo (PRT-ERP) argentino y el Ejército de Liberación Nacional Boliviano (ELN). Los capítulos "Dependencia o lucha armada. Intelectuales y militantes conosureños cuestionan el camino legal al socialismo. Santiago de Chile 1970-1973" y "La partida decisiva de la revolución en América Latina. Militantes bolivianos, chilenos y uruguayos en la Argentina peronista. Buenos Aires, 1973-1976”, recrean las agendas políticas y armadas de los grupos del sur, así como su inserción en contextos progresivamente autoritarios y dictatoriales.

Otro de los ejes centrales del texto es contrarrestar el exceso de visión sobre lo ideológico que no ha tenido en cuenta los aspectos políticos o agenciativos de estos grupos. Las organizaciones han sido estudiadas por dentro, pero no se han tenido en cuenta sus contactos o influencia en agendas políticas de la época ni tampoco las redes o discusiones que tejieron entre sí. De ahí que el historiador subraye la importancia de partir de la premisa de que los grupos armados de izquierda comenzaron a pensar su accionar desde una perspectiva regional. Estos nuevos vínculos que se trazaron apelaron a términos como "organizaciones hermanas" o "solidaridad revolucionaria” y demostraron nuevas formas en que la izquierda comenzaba a pensarse y vincularse entre sí. La red de estas organizaciones estableció un prolífico diálogo que tuvo su culmen en la creación de la Junta de Coordinación Revoluciona- 
ria, pero también se dieron discusiones y polémicas en cuanto a las distintas visiones sobre la lucha armada, las estrategias de una revolución a nivel continental o el internacionalismo proletario. Por último, el autor analiza los caminos de estas izquierdas tras la transición democrática, sus posibles accionares y el camino a la legalidad de muchos de estos grupos.

La amplia indagación en diferentes archivos es otra de las virtudes del libro de Marchesi. Entre las referencias podemos encontrar el Archivo de la Lucha Armada David Cámpora del Centro de Estudios Interdisciplinarios Uruguayos (CEIU), el Archivo de la Dirección de Inteligencia de la Provincia de Buenos Aires o el Archivo General Histórico del Ministerio de Relaciones Exteriores en Chile. El apoyo en fuentes hemerográficas, entrevistas, memorias y documentos de las organizaciones, sumado a una profusa bibliografía hace que sus ideas se fundamenten de manera ejemplar. Dentro de las hemerográficas destacan periódicos como El Combatiente, órgano del PRT-ERo, la revista chilena Punto Final, las uruguayas Marcha, Época, y Pasado y Presente, o Cristianismo y Revolución en Argentina. Todas, imprescindibles en los debates intelectuales y políticos de la época.

Hacer la Revolución... contribuye a la mayoría de las discusiones historiográficas que hoy tienen lugar sobre la historia del tiempo presente en América Latina. Algunas de sus principales propuestas se insertan en la renovación de esta área: el estudio de los movimientos guerrilleros desde un enfoque de redes; el análisis de los debates intelectuales dentro de la nueva izquierda en cuanto a la lucha armada y la estrategia continental; las distintas lecturas del proceso revolucionario cubano, así como sus distintos modos de afectar el sur; y, la confluencia entre las políticas regionales y los procesos globales. Su enfoque transnacional, fundamental para comprender la emergencia de los movimientos guerrilleros y de izquierda en la segunda mitad del siglo xx, resulta uno de los principales atractivos del texto. El diálogo que establece el libro con la obra de Eric Zolov, Claudia Gilman, Ariel C. Armony, 
John Dinges, Odd Arne Westad y Tanya Harmer hace que se ubique en un contexto historiográfico que ha enfocado su mirada en la historia política e intelectual en la América Latina del siglo xx. La historia que escribe Marchesi toma de la historia intelectual, de la historia política y de la historia del tiempo presente, y ese tipo de entrecruzamientos la hace aún más atractiva. 㕆 